\title{
MANAGEMENT OF RECENT UNSTABLE FRACTURES OF METACARPAL BONES OF THE HAND BY MINI-EXTERNAL FIXATOR
}

By

\author{
Ibrahim Hussein, Rashed E Rashed and Ahmed M Eita
}

Department of Orthopedic Surgery, Faculty of Medicine - Al-Azhar University

\begin{abstract}
Background: Metacarpal fractures either closed or open are common injuries and may account the most common fractures in the skeletal system. These fractures can be treated conservatively or operatively depending on the nature of the injury, fractures pattern and stability. Objective: To assess the functional outcome of injuries of metacarpal fractures after fixation by mini external fixator. Patients and Methods: This study was carried out on 15 patients presented with fractures in their metacarpals between February 2017 and November 2017 in the Orthopedics and Traumatology Department in Mahalla General Hospital. The study included. The mini-external fixator was used to fix the fractures within the first 24 hours and patients were followed up for 6-8 weeks with an average period of 7 weeks. Results: 13 patients were satisfied with this fixation by mini external fixator with full range of motion.
\end{abstract}

Key words: Unstable fractures, metacarpal bones, mini-external fixator.

\section{INTRODUCTION}

Hand injury is extremely common and accounts for about $15 \%$ of the attendance at accidents and emergency (Thakur, 2008).

Fractures of metacarpals are probably the most common fractures in the skeletal system and are often neglected as minor injuries (Kamath et al., 2011).

Fractures of the metacarpal bones are the most common fractures of the upper extremity that account $10 \%$ of total such cases. The outer rays of the hand are most commonly injured. The incidence of metacarpal fractures is common in males and peaks at the age 10-40 years when the athletic injury and industrial exposure is the greatest. Unfortunately the metacarpal fractures are often neglected or regarded as trivial injures. The proximal phalanx of the fingers is fractured more frequently than middle, distal and metacarpal bones. The deformity with considerable displacement is typical when the proximal phalanx is fractured (Watson and Barton, 2009).

Diagnosis of metacarpal fractures can be made after careful clinical assessment and radiological examination. Radiological examination should include standard anteroposterior and lateral views of the injured bones (Wong et al., 2008).

Patterns of injuries result from the unique anatomy of the hand. Metacarpals 
are long tubular bones with an intrinsic longitudinal arch and a collective transverse arch. Bones are concave on the palmar surface and are joined proximally and distally by ligamentous attachments (Bloom and Hammert, 2014).

Most of the fractures are treated conservatively, but some form of fixation is often indicated in unstable fractures, intra-articular fractures, open fractures, and multiple fractures. Various implants ranging from $\mathrm{K}$-wires, mini-plates to mini-external fixators are used to treat these fractures ( Dailiana et al., 2009).

Even though these fractures are small and more often neglected, these fractures causes significant deformity and disabilities. The management depends on the type, site, and pattern of fracture. The treatment options are conservative and operative. We have different types of surgical treatments such as open reduction and fixation with $\mathrm{K}$-wires, plates and screws, screws alone, and external fixators. Since mini-external fixation is less invasive and has the advantage of treating both open and closed fractures, we preferred mini external fixators for metacarpal fractures. Other advantages of external fixators are gives good stability for fracture, easy for wound care, and early mobilization of joints (Walter et al., 2008).

The aim of this study was to assess the functional outcome of injuries of metacarpal fractures after management by mini external fixator.

\section{PATIENTS AND METHODS}

This prospective study was undertaken to assess the functional outcome of injuries of metacarpal fractures after fixed by mini external fixator.

This study was done between February 2017 and November 2017 in the Orthopedics and Traumatology Department in Mahalla general hospital.

The material of this study included 15 patients presented with fractures in their metacarpals. The mini-external fixator was used to fix the fractures within the first 24 hours and patients were followed up for 6-8 weeks with an average period of 7 weeks.

\section{A) Inclusion criteria:}

1. Patients in the age group of between 10 and 60 years.

2. Unstable fractures.

3. Intra articular fractures and juxtraarticular fractures.

4. Open fractures.

5. Comminuted fractures.

6. Segmental bone loss.

7. Multiple fractures.

8. Patients who have given their written informed consent for the procedure.

\section{B) Exclusion criteria:}

1. Severely crushed hand injuries.

2. Fractures associated with Tendon injuries.

3. Fractures associated with Neurovascular injuries.

\section{Operative Treatment:}

I. Timing: All cases involved in this study were informed about the surgical procedure, a written consent was obtained and all patients were operated upon within the first 24 hours after the initial trauma. 


\section{Technique:}

Position: All patients were operated upon while lying in a supine position.

Anesthesia: The operation was carried out on 10 patients under general anesthesia while the remaining 5 patients were regionally anesthetized.

Intraoperative Fluoroscopy: Intraoperative imaging was used for all patients.

\section{Operative steps:}

Insertion of Primary Kirschner Wires: The skin and the subjacent soft tissue were incised and one $2.7 \mathrm{~mm}$ Kirschner wire was inserted proximally, and another one distally to the fracture. Using the Double Drill Sleeve the Kirschner wires were inserted until their tips were anchored in the far cortical bone and making sure that the Kirschner wires were aligned in one plane.

When using a drill, the Kirschner wires were inserted at low speed so as to avoid heat development. During the drilling process, the Kirschner wires were cooled with a saline or Ringer's solution. In proximity to joints, Kirschner wires were inserted using the Hand drill.

Positioning of Kirschner Wires: The anatomical situation of ligaments and tendons of the hand requires particular surgical caution. As a rule, the Kirschner wires were inserted into the metacarpals using a dorso-radial or a dorso-ulnar approach .

\section{Postoperative Measures:}

- The hand was elevated to promote maximal lymphatic and venous drainage to minimize the edema and thus diminishing the postoperative pain.

- Five days course of a broad spectrum antibiotic along with an analgesic were prescribed.

- Early motion was encouraged within the first 24 hours for all patients.

- Postoperative X-rays were done for all patients before discharge.

- Active and passive movements of the joints proximal and distal to the fracture were continued.

- After about four weeks, a radiological examination was done followed by removal of critical connecting rods and clinically testing for union. If there was no abnormal mobility or undue pain the frame was removed. If there is excruciating pain and abnormal motion at the fracture site, the frame was continued. This was repeated a week later and the frame was removed depending upon the presence of pain and abnormal mobility.

Rehabilitation: Joint mobilization was conditioned according to the fracture location and stability. The rehabilitation plan was individualized for every patient based on structural rigidity of fixation, patient compliance and the soft tissue edema postoperatively.

- In the securely fixed fractures, gentle active and passive motion was allowed as soon as tolerated by the patient.

- In comminuted, fractures the motions were cautiously allowed three weeks postoperatively.

Statistical analysis: Data were analyzed using Statistical Program for Social Science (SPSS) version 20.0. Quantitative data were expressed as mean \pm standard 


\section{IBRAHIM HUSSEIN et al.}

deviation (SD). Qualitative data were expressed as frequency and percentage. The confidence interval was set to $95 \%$ and the margin of error accepted was set to $5 \%$. So, the p-value was considered significant when $\mathrm{P}$ value $<$ or $=0.05$.

\section{RESULTS}

There were patients $\leq 25$ years $(20.0 \%),>25-35$ years $(33.3 \%),>35-40$ years $(20.0 \%)$ and $>40-50$ years $(26.7 \%)$ of age, while Female $(6.7 \%)$ and Male $(93.3 \%)$ of sex.The occupations were the worker (66.7\%), student (13.3\%), construction worker $(6.7 \%)$, farmer $(6.7 \%)$ and salesman $(6.7 \%)$ of occupation. There were non-smoker $(20 \%)$ and smoker $(80 \%)$. Mode of trauma was direct trauma $(86.7 \%)$ and high energy trauma $(13.3 \%)$ of mechanism of injury (Table 1).

Table (1): Demographic data distribution of the study group.

\begin{tabular}{|c|c|c|}
\hline Demographic Data & No. & $\%$ \\
\hline \multicolumn{3}{|l|}{ Age (years) } \\
\hline$\leq 25$ years & 3 & $20.0 \%$ \\
\hline$>25-35$ years & 5 & $33.3 \%$ \\
\hline$>35-40$ years & 3 & $20.0 \%$ \\
\hline$>40-50$ years & 4 & $26.7 \%$ \\
\hline Range $[$ Mean \pm SD] & \multicolumn{2}{|c|}{$13-50[35.13 \pm 11.12]$} \\
\hline \multicolumn{3}{|l|}{ Sex } \\
\hline Female & 1 & $6.7 \%$ \\
\hline Male & 14 & $93.3 \%$ \\
\hline Occupation & No. & $\%$ \\
\hline Worker & 10 & $66.7 \%$ \\
\hline Student & 2 & $13.3 \%$ \\
\hline Construction worker & 1 & $6.7 \%$ \\
\hline Farmer & 1 & $6.7 \%$ \\
\hline Salesman & 1 & $6.7 \%$ \\
\hline Total & 15 & $100.0 \%$ \\
\hline Smoker & No. & $\%$ \\
\hline Non smoker & 3 & $20.0 \%$ \\
\hline Smoker & 12 & $80.0 \%$ \\
\hline Total & 15 & $100.0 \%$ \\
\hline Mechanism of injury & No. & $\%$ \\
\hline Direct Trauma & 13 & $86.7 \%$ \\
\hline High Energy Trauma & 2 & $13.3 \%$ \\
\hline Total & 15 & $100.0 \%$ \\
\hline
\end{tabular}




\section{MANAGEMENT OF RECENT UNSTABLE FRACTURES OF METACARPAL... 39}

Affected hands were left (53.3\%) and right $(46.7 \%)$ of affected hand, also dominant $(46.7 \%)$ and non-dominant $(53.3 \%)$ of dominant hand. Types of fracture were closed $(40 \%)$ and open $(60 \%)$ of type of fracture, while comminuted (40\%), oblique $(6.7 \%)$, short oblique $(6.7 \%)$ and transverse $(46.7 \%)$ of shape of fracture.
Distributions of fracture were the $1 \mathrm{st}$ metacarpal (6.7\%), 2nd metacarpal (13.3\%), 3rd metacarpal (33.3\%), 4th metacarpal $(40.0 \%)$ and 5th metacarpal $(33.3 \%)$. Deformity of fracture after fixation was with deformity (13.3\%) and without deformity (86.7\%) (Table 2).

Table (2): Affected hand, type of fracture, distribution of fracture, associated deformity.

\begin{tabular}{|c|c|c|}
\hline & No. & $\%$ \\
\hline \multicolumn{3}{|l|}{ Affected hand } \\
\hline Left & 8 & $53.3 \%$ \\
\hline Right & 7 & $46.7 \%$ \\
\hline \multicolumn{3}{|l|}{ Dominant hand } \\
\hline Dominant & 7 & $46.7 \%$ \\
\hline \multirow[t]{2}{*}{ Non Dominant } & 8 & $53.3 \%$ \\
\hline & No. & $\%$ \\
\hline \multicolumn{3}{|l|}{ Type of fracture } \\
\hline Closed & 6 & $40.0 \%$ \\
\hline Open & 9 & $60.0 \%$ \\
\hline \multicolumn{3}{|l|}{ Shape of fracture } \\
\hline Comminuted & 6 & $40.0 \%$ \\
\hline Oblique & 1 & $6.7 \%$ \\
\hline Short oblique & 1 & $6.7 \%$ \\
\hline Transverse & 7 & $46.7 \%$ \\
\hline Distribution of the fracture & No. & $\%$ \\
\hline 1st metacarpal & 1 & $6.7 \%$ \\
\hline 2nd metacarpal & 2 & $13.3 \%$ \\
\hline 3rd metacarpal & 5 & $33.3 \%$ \\
\hline 4th metacarpal & 6 & $40.0 \%$ \\
\hline 5th metacarpal & 5 & $33.3 \%$ \\
\hline Deformity & No. & $\%$ \\
\hline With Deformity & 2 & $13.3 \%$ \\
\hline Without Deformity & 13 & $86.7 \%$ \\
\hline Total & 15 & $100.0 \%$ \\
\hline
\end{tabular}


Satisfaction of patients after fixation were satisfactory $(86.7 \%)$ and unsatisfactory $(13.3 \%)$ of overall end results. Duration of radiological union were united in 6 weeks
(53.3\%), united in 7 weeks (40\%) and nonunion $(6.7 \%)$ of radiological union. Final end results were excellent $(66.7 \%)$, good $(20 \%)$, fair $(6.7 \%)$ and poor $(6.7 \%)$ (Table 3).

Table (3): Overall end results, radiological union and final end results.

\begin{tabular}{|l|c|c|}
\hline Overall end results & No. & \% \\
\hline Satisfactory & 13 & $86.7 \%$ \\
\hline Unsatisfactory & 2 & $13.3 \%$ \\
\hline Total & 15 & $100.0 \%$ \\
\hline Radiological Union & No. & \% \\
\hline United in 6 weeks & 8 & $53.3 \%$ \\
\hline United in 7 weeks & 6 & $40.0 \%$ \\
\hline Non union & 1 & $6.7 \%$ \\
\hline Total & 15 & $100.0 \%$ \\
\hline Final End Results & No. & $\%$ \\
\hline Excellent & 10 & $66.7 \%$ \\
\hline Good & 3 & $20.0 \%$ \\
\hline Fair & 1 & $6.7 \%$ \\
\hline Poor & 1 & $6.7 \%$ \\
\hline Total & 15 & $100.0 \%$ \\
\hline
\end{tabular}

There were no statistically significant relations between final end results and affected hand (Table 4).

Table (4): Statistical end results between affected hands and final end results.

\begin{tabular}{|c|c|c|c|c|c|c|c|c|}
\hline \multicolumn{2}{|c|}{ Affected hand } & \multicolumn{4}{|c|}{ Final End Results } & \multirow[t]{2}{*}{ Total } & \multicolumn{2}{|c|}{ Chi-square test } \\
\hline & & Excellent & Good & Fair & Poor & & $\mathbf{x} 2$ & p-value \\
\hline \multirow[t]{2}{*}{ Left } & No. & 6 & 2 & 0 & 0 & 8 & \multirow{6}{*}{2.679} & \multirow{6}{*}{0.444} \\
\hline & $\%$ & $40.0 \%$ & $13.3 \%$ & $0.0 \%$ & $0.0 \%$ & $53.3 \%$ & & \\
\hline \multirow[t]{2}{*}{ Right } & No. & 4 & 1 & 1 & 1 & 7 & & \\
\hline & $\%$ & $26.7 \%$ & $6.7 \%$ & $6.7 \%$ & $6.7 \%$ & $46.7 \%$ & & \\
\hline \multirow[t]{2}{*}{ Total } & No. & 10 & 3 & 1 & 1 & 15 & & \\
\hline & $\%$ & $66.7 \%$ & $20.0 \%$ & $6.7 \%$ & $6.7 \%$ & $100.0 \%$ & & \\
\hline
\end{tabular}


MANAGEMENT OF RECENT UNSTABLE FRACTURES OF METACARPAL... ${ }^{41}$
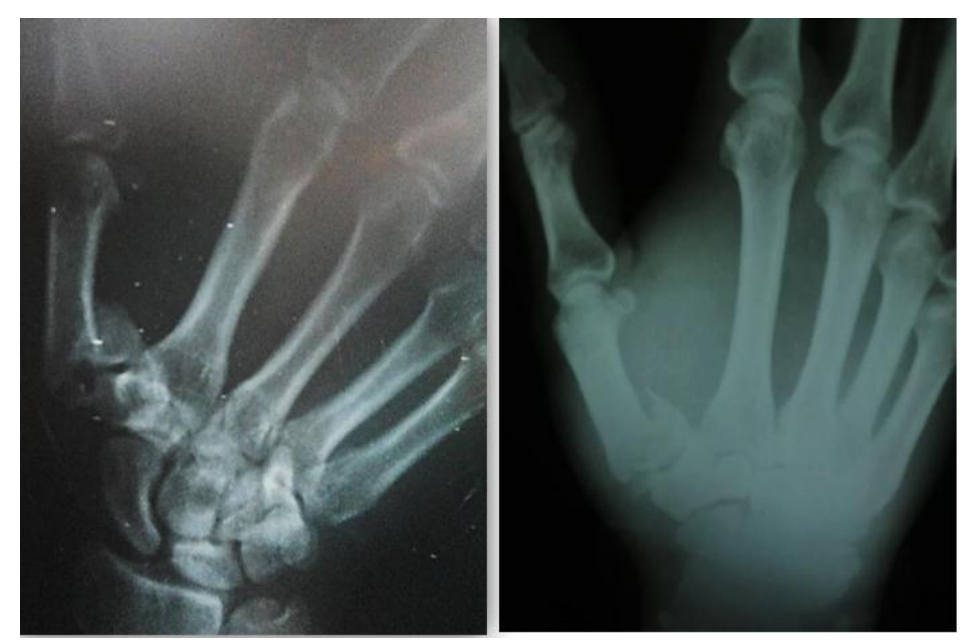

Figure (1): Antero-posterior and oblique radiographs showing Rolando fracture in the base of first metacarpal of the right hand.



Figure (2): Intraoperative antero-posterior view off the image intensifier screen showing the application of the three wires and an adequate fracture reduction was achieved.

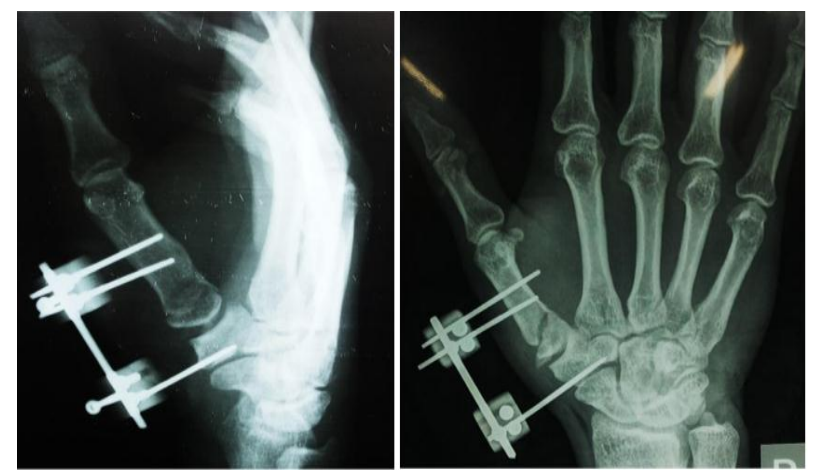

Figure (3): Immediate postoperative antero-posterior and oblique radiographs showing the reduction and the mini fixator application.

\section{DISCUSSION}

Hand injuries are common and usually result in metacarpal fractures. These injuries usually occur in adolescents and active young patients. Metacarpal fractures constitute $15-28 \%$ of all cases referring to the emergency department. Fractures of the metacarpal bones 
IBRAHIM HUSSEIN et al.

constitute $10 \%$ of all fractures. Although these fractures are considered minor injuries, such injuries may cause major disabilities ( Mohammed et al., 2011).

Failure to gain union following a metacarpal fracture is rare, concomitant problems present a different story (Emmett and Breck, 2010).

Functional outcomes depend on the severity of the injury and achievement of the treatment.

Most of these fractures can be treated conservatively, but in a relatively small number of patients with unstable fractures operative treatment is indicated. There are two types of fixation: internal according to Arbeitsgemeinschaft fur Osteosynthesefragen (AO) standards, and external for a selected group with open unstable fractures or severe soft-tissue injuries (Thomas et al., 2008).

A fracture is considered functionally stable when during clinical examination; it is possible to actively move the fractured digit by $50 \%$ of range of motion painlessly. The fracture is considered radiologically stable when the radiographs of the fractured fragment in two planes show minimum angulation and displacement. A fracture is considered unstable if it cannot be reduced or maintained in an anatomic or near anatomic position without implant fixation when the hand is placed in the safe or functional position (Venkataswami, 2009).

Many techniques have been described for surgical treatment of metacarpal fractures including cross pinning, L pinning, transverse Kirschner wires, intraosseous wiring, expandable rods, cerclages, intramedullary pinning, external fixation, plates and screws fixation (Ramsey et al., 2010).

We used external fixation to help to avoid any additional injury to the bone and soft tissues. The technique is relatively simple, and even greater precision is added by the use of an image intensifier (Posner, 2011).

The use of external fixators in metacarpal fractures is usually reserved for open fractures with severe soft tissue injury/loss. The technique is relatively simple and avoids further trauma to the surrounding tissues.

In this study, the mini external fixator was used to help avoiding injury to bone and soft tissues. The technique was relatively simple; an image intensifier made placement of pins more accurate and less complications. The best site for pin introduction was best chosen and the operating time was reduced. In addition, the stable frame allowed early mobilization that improved the range of motion, and it was easily removed as an outpatient procedure.

The use of mini external fixator in management of metacarpal fractures had been increasingly stressed upon by many authors such as (Dailiana et al., 2009)

The current study included 15 patients presented with 15 metacarpal fractures, their age was between 13 and 55 years, The age of patients was ranged from 15 to 69 years; and ranged from 17 to 74 years (Dailiana et al., 2009). 


\section{MANAGEMENT OF RECENT UNSTABLE FRACTURES OF METACARPAL... ${ }^{43}$}

In the presented study, $14(60.86 \%)$ fractures were open and nine (38.14\%) fractures were closed (Dailiana et al., 2009) reported $23(38.9 \%)$ patients with open fractures.

In this work, the most common mechanism of injury was direct trauma either by impaction or crushing in 13 patients $(80.9 \%)$ which were most probably due to falling of heavy objects on the hand, or indirect trauma in the form of twisting injury in 2 patients (19.1\%). However in the study presented by Day (2017) the most common mechanism of injury was road traffic accident in 9 patients $(25 \%)$.

In this study, all fractures were operated in the same day of injury and time lapse ranged from two to eight hours. However in the study reported by Chin et al., 2008 and Dailiana et al., 2009, the time lapse ranged between one to 20 days and from five to ten days respectively.

In the presented study, the mean range of union was between three and 12 weeks. This was nearly the same as the study of Dailiana et al. (2009) and Li et al. (2009) study in which union ranged between 3 and 12 weeks.

The results of the presented study were excellent in $(57.14 \%)$ and poor in $(9.52 \%)$ (Table-8). This was nearly the same results reported by Belsky et al. (2011) showing 12 excellent/good, 3 fair, 6 poor. In this work, the results of metacarpal fracture were ffive excellent (23.81\%) and three $(14.28 \%)$ fair); the results of proximal phalanges (five excellent $(50 \%)$, two good $(20 \%)$, two fair $(20 \%)$ and one poor $(10 \%)\}$ and the results of middle phalanges were (two excellent $(40 \%)$ and three $(60 \%)$ good).

In this study, the external fixator was removed after four weeks in three patients (14.28\%); five weeks in nine patients $(42.85 \%)$, six weeks in four $(19.04 \%)$, seven weeks in four $(19.04 \%)$ and eight weeks in one patient $(4.76 \%)$; but Dailiana et al. (2009) removed the device at a mean of 5.8 weeks (range: $3-11$ ) after metacarpal fractures and 6.1 (range: 2-12 weeks) after metacarpal fractures, 3.7 (range: 2.7-6) weeks and 6 (range 5-12 weeks) respectively.

The satisfactory results in patients where the fixators were removed after four weeks were $100 \%$ and in those where the fixators were removed after five weeks were $66.7 \%$ however unsatisfactory results were $33.3 \%$ and patients where the fixators were removed after six weeks. And this explains that the longer the period of fixation the worse were the results.

In this study, there were seven patients $(33.3 \%)$ manifested with complications during the follow up period, which varied from nonunion, joint stiffness, infection, mal-union and delayed union.

Dailiana et al. (2009) had two patients presented with superficial pin tract infection; mal-union occurred in one patient, three presented with reflex sympathetic dystrophy and one patient developed hypertrophic callus.

In the present study non-union was presented in two of the patients $(9.52 \%)$ treated in this study. The other patient was 
a male who was heavy smoker and he had fracture of his second metacarpal.

Non-union was also reported by Balaram and Bednar (2010) especially in open fractures. As regard infection it was reported as pin tract infection by Dailiana et al. (2009) and Li et al. (2009) study and also in the presented study. This was easily controlled by dressing and antibiotics.

In the present work, only one $(4.76 \%)$ patient had a superficial pin tract infection which was discovered at the time of removal of the fixator and resolved by oral antibiotic administration for one week.

MCP joint stiffness is a frequent problem following the treatment of metacarpal head fractures. This problem is minimized by achieving a stable anatomic reduction allowing early motion (Balaram and Bednar, 2010).

Nearly all patients treated in this study were satisfied with their results and returned back to their daily activities. This was nearly the results reported by Kollitz et al. (2014).

\section{CONCLUSION}

Mini external fixator is an adequate modality for unstable metacarpal fractures. It is easily applied and allows early mobilization of the surrounding joints which prevents stiffness. Pins should be watched closely during the period of fixation to avoid pin tract infection and loosening.

\section{REFERENCES}

1. Balaram AK and Bednar MS (2010): Complications after the fractures of metacarpal and phalanges. Hand Clin, 26(2):169-77.

2. Belsky MR, Eaton RG and Lane LB (2011): Closed reduction and internal fixation of metacarpal fractures. J Hand Surg [Am], 9:725-9.

3. Bloom JM and Hammert WC(2014): Evidence-based medicine: Metacarpal fractures. Plast Reconstr Surg., 133 (5):125260.

4. Chin SH, Vedder NB and MOC-PSSM CME (2008): Metacarpal fractures. Plast Reconstr Surg. 121(1 Suppl):1-13.

5. Day CS (2017): Fractures of the metacarpals and phalanges. Wolfe SW, Hotchkiss RN, Pederson WC, eds. Green's Operative Hand Surgery. 7th ed. Pbl Philadelphia: Elsevier; Vol 1: 231-77.

6. Dailiana Z, Agorastakis D, Varitimidis S, Bargiotas $\mathrm{K}$, Roidis $\mathbf{N}$ and Malizos $\mathrm{KN}$ (2009): Use of a mini-external fixator for the treatment of hand fractures. J Hand Surg Am., 34:630-6.

7. Emmett JE and Breck LW (2010): A review and analysis of 11,000 fractures seen in a private practice of orthopaedic surgery. J Bone Joint Surg., 40-A: 1169.

8. Kamath JB, Harshvardhan, Naik DM and Bansal A (2011): Current concepts in managing fractures of metacarpal and phalangess. Indian J Plast Surg., 44:203-11.

9. Kollitz KM, Hammert WC, Vedder NB, Huang JI (2014): Metacarpal fractures: treatment and complications. Hand $(N \quad Y)$, 9(1):16-23.

10. Li WJ, Tian W and Tian GL (2009): Management of intra-articular fractures of the fingers via mini external fixator combined with limited internal fixation. Chin Med J (Engl), 122 (21):2616-9. 
MANAGEMENT OF RECENT UNSTABLE FRACTURES OF METACARPAL... ${ }^{45}$

11. Mohammed R, Farouk MZ and Newman $K$ (2011): Percutaneous elastic intramedullary nailing of metacarpal fractures: surgical technique and clinical results study. J Orthop Surg Res., 6: P: 37.

12. Posner MA (2012): Injuries to the hand and wrist in athletes. Orthop Clin North Am., 8:593-618.

13. Ramsey H, Peter BM and Ali K (2010): Single Retrograde Intramedullary Wire Fixation of Metacarpal Shaft Fractures. Acta Orthop., 76: 751-7.

14. Thakur A (2008): Operative management of metacarpal and phalangeal fractures. J Med Educ Res ;10:1-9.

15. Thomas RK, Gaheer RS and Ferdinand RD (2008): A simple external fixator for complex finger fractures. Acta Orthop., 74: 109-13.

16. Venkataswami $R$ (2009): Surgery of the Injured Hand-Towards Functional Restoration. $1^{\text {st }}$ ed. New Delhi, India: Jaypee Publishers, $p$. 409.

17. Walter FL and Papandrea RF (2011): A mini external fixator for hand and finger fractures constructed from readily available materials. Tech Hand Up Extrem Surg., 15:215-8.

18. Watson-Jones $R$ and Barton NJ (2009): Fractures and Joint Injuries of the hand. In: Wilson JN, editor. Watson-Jones fractures and joint Injuries. $7^{\text {th }}$ ed. Noida: Elsevier Publishers, P: 650-95.

19. Wong HK, Lam CY and Wong KY(2008): Treatment of phalangeal and metacarpal fractures: A review. J Orthop., 10:42-50. 


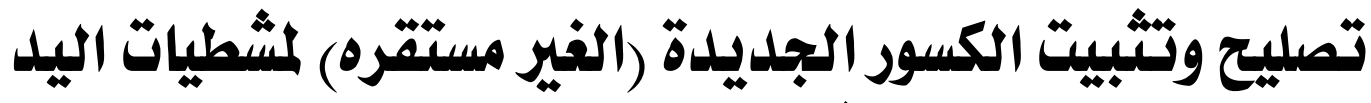 بمثبثت خارجي صنير}

إبر اهيم حسين-راشد إمام راشد_أحمد محمد عبد الخالق عيطه

قسم جراحة العظام ـ كلية الطب-جامعة الأزهر

خلفيـة البحث : تعتبر اليد من أكثر أجزاء الجسم تعرضـا للكسور وخاصـة في مجـالات الصناعة الصنا

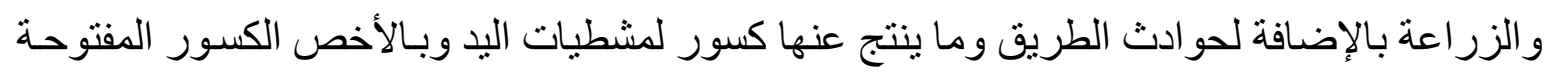
المفتتة .

الهلف من البحث: تثبيت كسور مشطيات اليد عن طريق مثبت خـارجي صغير ومعرفة مميزات ونتائج هذا التثبيث.

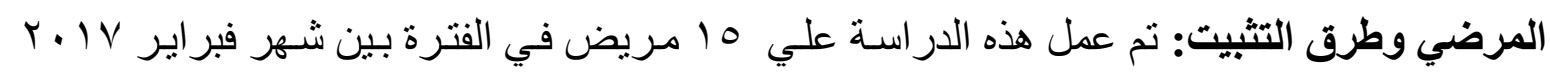

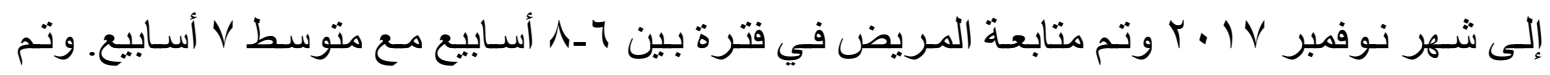

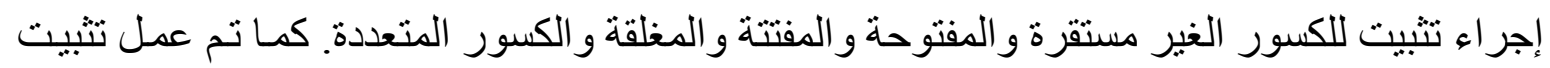

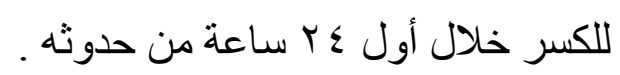

بوضع سلك معدني مقاس Y, Y مم أعلى الكسر وآخر أسفل الكسر ثم وضع جهاز المثبت وعمل



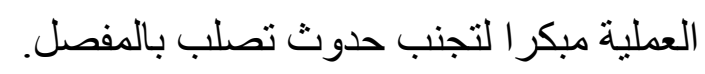

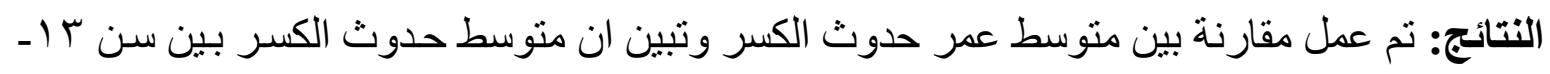

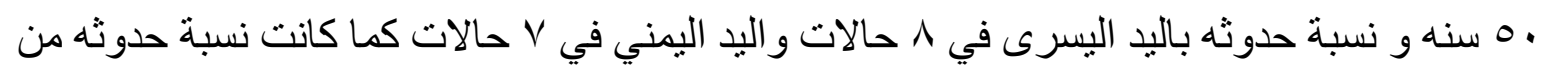

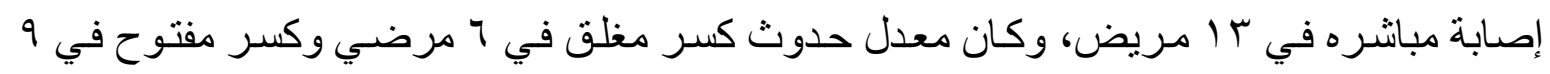

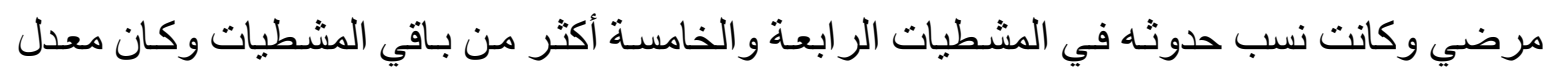
التئام الكسر في 1 أسابيع في ^ مرضي مرضي وفي ل أسابيع في 7 مرضي.

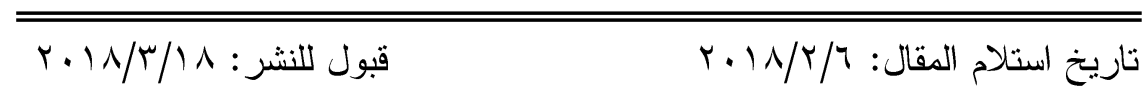

